\title{
A aula de História como lugar do ensino, da pesquisa e da extensão
}

\author{
Ronaldo Cardoso Alves*
}

\section{Resumo}

\begin{abstract}
O artigo apresenta um projeto de trabalho desenvolvido pelo Laboratório de Estudos e Pesquisas em Didática da História da Unesp/campus Assis (LEPEDIH), no qual a sala de aula é compreendida como lugar de construção do conhecimento histórico por meio de experiências entre estudantes, professores e futuros professores, que agregam o ensino, a pesquisa e a extensão, de forma que ocorra a aproximação entre universidade e escolas públicas de ensino básico com o fim de que seus participantes possam relacionar o estudo da História com a própria vida.
\end{abstract}

Palavras-chave: Consciência histórica. Representações sociais. Etnografia educacional.

O Laboratório de Estudos e Pesquisas em Didática da História, da Unesp campus Assis (LEPEDIH), tem atuado em diferentes frentes de trabalho, com o objetivo de suscitar novos pesquisadores do ensino de História com base em iniciativas de pesquisa que partam do interior do espaço escolar, entendendo-o como lócus de construção de saberes que agregue o tripé sustentáculo da universidade brasileira, qual seja: ensino, pesquisa e extensão. Tal iniciativa parte da premissa da necessidade premente de aproximação da universidade brasileira às escolas públicas de ensino básico. Nesse sentido, pode-se pensar no professor de História como um gerador de iniciativas que promovam a aproximação do estudo da História dos problemas cotidianos, locais e globais, aos quais são submetidos seus estudantes? É possível suscitar iniciativas que mostrem às crianças e aos adolescentes estudantes de escolas públicas de ensino básico no Brasil que a universidade pública é também para elas? Qual o papel do professor de História dentro desse processo?

Antes mesmo da criação do Programa Institucional de Bolsa de Iniciação à Docência (Pibid) por parte do Ministério da Educação (MEC), coordenado pela Co-

Recebido: 05/06/2014 - Aprovado: 07/07/2014

http://dx.doi.org/10.5335/rep.v21i2.4301

Professor Assistente Doutor do Departamento de Educação da Faculdade de Ciências e Letras - Universidade Estadual Paulista "Júlio de Mesquita Filho" (Unesp - Campus Assis). Coordenador do Subprojeto de História do Pibid, do Laboratório de Estudos e Pesquisas em Didática da História (LEPEDIH) e do Projeto de Educação de Jovens e Adultos (Peja) no mesmo campus.E-mails: ronaldocardoso@assis.unesp.brou ronaldoc_br@yahoo.com.br. 
ordenação de Aperfeiçoamento de Pessoal de Ensino Superior (Capes) - importante programa que se espalhou pelas universidades e escolas de educação básica do país, cujo principal objetivo é qualificar a formação dos futuros professores, estudantes dos cursos de licenciatura, por meio da aproximação entre universidade e escola básica, a Universidade Estadual Paulista Júlio de Mesquita Filho conta com um programa de perfil similar, gerador de oportunidades de intercâmbio desses entes, em diferentes áreas do conhecimento e seriações, nas escolas públicas do estado de São Paulo. ${ }^{1}$

O Núcleo de Ensino da Universidade Estadual Júlio de Mesquita Filho (Unesp) é um programa que agrega, há mais de uma década, projetos de ensino desenvolvidos nos cursos de licenciatura, de diversas áreas do conhecimento, em várias unidades da Unesp distribuídos pelo estado de São Paulo. Seu objetivo é aproximar a universidade da escola básica com o fim de qualificar o ensino público paulista e a formação docente nos cursos de licenciatura em seus diferentes campi.

O presente artigo trata de um projeto que está em pleno desenvolvimento pelo LEPEDIH, no Núcleo de Ensino da Unesp da Faculdade de Ciências e Letras de Assis, intitulado $O$ uso das linguagens no ensino de História como meio de aprendizagem: um desafio ao professor-pesquisador. Seu objetivo é auxiliar o professor de História da unidade escolar, os licenciandos deste curso e os bolsistas do projeto a elaborarem atividades que utilizem diferentes fontes históricas para a construção do conhecimento histórico dos estudantes, bem como oferecer elementos teórico-metodológicos que suscitem possibilidades de pesquisa, as quais tenham como objetivo a interpretação das representações sociais dos estudantes derivadas desse processo de trabalho.

O projeto teve início em abril de 2013 com a realização de reuniões entre a coordenação (o professor da universidade, autor deste artigo), dois bolsistas (licenciandos do curso de História) e a professora de História da unidade escolar participante, com o fim de estabelecer as temáticas abordadas nas ações didáticas a serem elaboradas, bem como as turmas (e séries) que participariam do trabalho. A professora lecionava, àquela altura, para turmas do $1^{\circ}$ e $2^{\circ}$ ano do ensino médio. Dessa forma, o projeto passou a ter duas frentes, com um bolsista designado para cada série com o fim de, em um primeiro momento, acompanhar as aulas, interagir com o grupo de estudantes, ou seja, conhecer aspectos do cotidiano da escola, da sala de aula, da comunidade intra e extraescolar, do convívio entre docentes e estudantes, funcionários, pais, etc. Processo de ambientação fundamental para que as ações didáticas e os instrumentos de pesquisa a serem elaborados considerassem o perfil do grupo de forma tal que, efetivamente, pudessem auxiliar os estudantes a relacionarem o estudo da História com sua própria vida. 
Um repertório teórico-metodológico é constituido com a finalidade de subsidiar todas as etapas do trabalho. Inicialmente, fundamentou a elaboração de ações didáticas, cujo objetivo central é o uso de diferentes linguagens como fontes históricas para a construção do conhecimento. Em um segundo momento, ofereceu subsídios aos instrumentos de pesquisa que visavam à construção do perfil do grupo de estudantes participantes do trabalho com o fim de possibilitar, ao professor da escola e aos bolsistas-licenciandos, a interpretação das representações sociais por esses geradas a partir da aplicação das ações didáticas. Finalmente, com base nesse processo, tal repertório objetivou gerar possibilidades de pesquisa em ensino de História aos bolsistas-licenciandos. Para a consecução desse intento, o repertório teórico-metodológico promoveu a relação entre contribuições oriundas de estudos etnográficos voltados à educação, das representações sociais e da consciência histórica.

Ao adentrar as salas de aula, os bolsistas-licenciandos utilizaram-se de alguns recursos de inspiração etnográfica, pois esses envidam possibilidades de interpretação de diferentes representações geradas na coletividade que se pretende estudar. A etnografia visa não somente a verificação do que é aparente, mas, sobretudo, a revelação do que é latente em uma cultura - ou seja, aquilo que não pode ser apreendido à primeira vista. Nessa perspectiva, o objetivo da etnografia é "[...] tirar grandes conclusões a partir de fatos pequenos, mas densamente entrelaçados; apoiar amplas afirmativas sobre o papel da cultura na construção da vida coletiva empenhando-as exatamente em especificações complexas" (GEERTZ, 2012, p. 38).

Exemplo dessa prática é a clássica pesquisa desenvolvida por Norbert Elias e John Scotson (2001) junto a uma pequena comunidade situada em um vilarejo industrial na Inglaterra, no final da década de 1950, em que, baseados em recursos etnográficos e qualitativos, estudaram as relações sociais dos diferentes grupos que a compunham com o fim de compreender, por meio das representações de seus integrantes, como eram organizadas as relações de poder, as hierarquizações, os mecanismos de resistência à opressão, às mudanças e, ainda, as permanências de mentalidade, entre outros aspectos inerentes aos (des)encontros dos seres humanos no tempo. Para que alcançassem seus objetivos fez-se necessário "[...] aprender a observar e conceituar sistematicamente o modo como os indivíduos se agregam, como e porque as configurações assim formadas se modificam e, em alguns casos, se desenvolvem" (ELIAS; SCOTSON, 2001, p. 57). Para tanto, lançaram mão de diferentes recursos etnográficos como a observação participante (o pesquisador adentra o espaço estudado e interage com seus sujeitos) e a realização de anotações de campo com a finalidade de obter consistente material para compreender as diferentes características e a dinâmica das relações do grupo estudado. Assim, o recurso etnográfico possibilita a descrição densa de um objeto de estudo. Entende-se como 
descrição densa a prática realizada pelo etnógrafo com o objetivo de perceber a “[...] multiplicidade de estruturas conceptuais complexas, muitas delas sobrepostas ou amarradas umas às outras, que são simultaneamente estranhas, irregulares e inexplícitas, e que ele tem que, de alguma forma, primeiro apreender e depois apresentar" (GEERTZ, 2012, p. 20).

A escola também pode ser um lugar a ser descrito densamente. $O$ etnógrafo, ao adentrar esse espaço para desenvolver seu trabalho, depara-se com estruturas conceituais que se intersectam e formam a identidade da escola. Diversos pesquisadores, desde as últimas décadas do século XX, têm se debruçado em desenvolver possibilidades de pesquisa etnográfica no âmbito educacional de forma a, efetivamente, relacionarem o repertório teórico-metodológico da etnografia ao contexto escolar. Destacam-se, aqui, as pesquisas desenvolvidas no cenário latino-americano, mais precisamente em escolas mexicanas por Elsie Rockwell e Justa Ezpeleta. Para estas autoras, é fundamental que o pesquisador interaja com o espaço educacional, a fim de defrontar-se com seus desafios, entendendo-se não como aquele que estuda o objeto com vistas a modificá-lo de acordo com seus objetivos, mas (e, sobretudo) como alguém que esteja aberto a modificar suas próprias preconcepções, a partir de seu encontro com o objeto de estudo, no caso, o contexto escolar.

"A experiência de campo e o trabalho analítico devem mudar-nos, devem mudar a nossa maneira de olhar a realidade escolar. Por esse meio, sua contribuição encontra-se no terreno conceitual e depende da perspectiva teórica a partir da qual se descreve e se interpreta a realidade educativa" (ROCKWELL, 1986, p. 22).

Ao estudar a vivência dos grupos que compõem essa instituição, em sua dinâmica de encontros e confrontos, o pesquisador relaciona-se diretamente com aquele espaço de experiência (KOSELLECK, 2006) ${ }^{2}$ e, consequentemente, gera possibilidades de interpretação da teia de significados que constituem as especificidades inerentes ao grupo que, historicamente, se constituiu naquele lugar. Em outras palavras, ao trabalhar com recursos de inspiração etnográfica na escola, o investigador utiliza-se de ferramentas que lhe permitem conhecê-la em sua historicidade. Todo espaço escolar surge como consequência de demandas de uma comunidade constituída por aspectos peculiares, mesmo que atravessada por políticas públicas pretensamente homogeneizantes, pois é formada por indivíduos que criam sua relação com o lugar ao longo do tempo, ou seja, criam uma identidade. Assim, uma escola localizada na periferia de uma grande cidade guarda semelhanças com outras com essa mesma característica, porém, certamente apresenta especificidades que podem gerar infinitas possibilidades de (investig)ação àqueles que a compõem. Nesse sentido, a etnografia educacional pode oferecer não somente aos pesquisadores, mas tambéme, principalmente, aos habitantes do espaço escolar - professo- 
res, gestores, estudantes, comunidade - a oportunidade de compreenderem a teia de significados que representa a identidade do grupo. Como afirma Bueno (2007, p. 487) em um diálogo com os escritos de Ezpeleta e Rockwell (1986): “[...] cada estabelecimento de ensino é uma versão local de um movimento social mais abrangente. Ou seja, embora a escola não seja mero reflexo desse movimento, não pode ser entendida sem a necessária referência ao contexto social e político que lhe dá existência e sentido". Pensar a escola em sua historicidade cotidiana implica, desse modo, concebê-la como "[...] história não documentada, através da qual a escola toma forma material e ganha vida. Nesta história, a determinação e presença estatal se entrecruza com as determinações e presenças civis” (EZPELETA; ROCKWELL, 1986, p. 13).

Assim, recursos de inspiração etnográfica possibilitam estudar o âmbito escolar com a finalidade de interpretar representações sociais desse originadas. Permite àqueles que querem refletir a respeito de tal complexidade pensarem não somente no que aparece no discurso de professores, estudantes, gestores, entre outros, mas também naquilo que está implícito, oculto, "mascarado", em uma primeira análise. É o desafio de desvelar a multiplicidade de elementos que estão, explícita e implicitamente, presentes no discurso, formadores de símbolos que pretendem transformar o pensamento em uma "representação do real” (PESAVENTO, 1995, p. 18).

Roger Chartier (1990) conceitua representação como um instrumento da história cultural que permite estudar as diferentes "classificações, divisões e delimitações que organizam a apreensão do mundo social como categorias fundamentais de percepção e de apreciação do real" (p. 17) nos indivíduos e na pluralidade de grupos que se articulam na sociedade.

As representações possibilitam classificar e delimitar a multiplicidade de configurações intelectuais que constroem o cotidiano de diferentes grupos. Além disso, permitem reconhecer a maneira em que os grupos se identificam socialmente, por meio das diferentes expressões simbólicas que revelam suas formas de ser e estar no mundo. Essas representação também são importantes na averiguação dos mecanismos que as instituições utilizam para marcar, de forma visível, sua existência enquanto classe, grupo ou comunidade.

Denise Jodelet caracteriza a representação social como "[...] uma forma de conhecimento, socialmente elaborada e partilhada, com um objetivo prático, e que contribui para a construção de uma realidade comum a um conjunto social" (JODELET, 2001, p. 22). Designado pela autora como saber do senso comum, “[...] esta forma de conhecimento é diferenciada, entre outras, do conhecimento científico. Entretanto, é tida como um objeto de estudo tão legítimo quanto este, devido à sua importância na vida social e à elucidação possibilitadora dos processos cognitivos e das interações sociais" (JODELET, 2001, p. 22). 
Para Serge Moscovici, as representações sociais constituem-se como uma verdadeira "teoria do senso comum" (MOSCOVICI, 1976, p. 48) elaborada por uma "sociedade pensante" (MOSCOVICI, 2003, p. 43) que cria e, ao mesmo tempo, é influenciada por representações. Essa dupla característica mostra que o conhecimento também é gerado na simplicidade das relações humanas e no encontro com o outro. Nessa perspectiva, o ato de pensar não se restringe somente à formalidade dos espaços acadêmicos, mas apresenta-se também na convivência cotidiana, no todo social.

Destarte, estudar representações sociais implica adentrar a densidade de um espaço que (re)apresenta os seres humanos em seus pensamentos, em suas formas de estar e de compreender o mundo, em seus questionamentos, em suas opções históricas, independentemente de suas características socioeconômicas, culturais ou políticas. Portanto, as representações tornam-se sociais quando levam em consideração diferentes aspectos da sociedade, principalmente o conhecimento gerado que comumente é denominado de senso comum.

Observa-se, portanto, que recursos de inspiração etnográfica auxiliam no processo de desvelamento de diferentes representações sociais a partir da descrição densa das práticas constituintes, de um determinado grupo social, em sua inserção no tempo de longa duração (BRAUDEL, 1992). Historicamente, poderíamos pensar nas instâncias de mudanças e permanências ou mesmo nas adequações e/ ou apropriações de símbolos criados para representar pensamentos ao longo do tempo, fornecendo, assim, credibilidade às representações sociais de um grupo. Suas ideias precisam, necessariamente, relacionar-se com o mundo vivido. Seus símbolos devem ser construídos a partir da realidade cotidiana para que tenham aceitação social. A partir disso, dois caminhos são possíveis para a utilização da representação social por um grupo e, consequentemente, para a expansão dessa simbologia cognitivamente criada para toda a sociedade: o da resistência utópica, expressada em sonhos a serem conquistados e o da manipulação ideológica, obtida a partir da cristalização dos ideais e da manipulação dos símbolos com vistas à manutenção do poder.

Nessa perspectiva, o projeto propõe entender os sujeitos do espaço escolar como agentes que, muitas vezes, se perdem no anonimato da mentalidade de homogeneidade e carecem de espaços que façam ressoar suas vozes. Prioriza o coletivo em detrimento do individual no intuito de compreender o estudante inserido em um "conjunto de relações sociais que conforma seu mundo particular" (EZPELETA; ROCKWELL, 1986, p. 24). No mundo da globalização, da expansão de uma lógica neoliberal de vida, da luta de culturas que se encontram no espaço dialético da homogeneização global de um lado e da excentricidade local de outro, em que medida 
instituições modernas como a escola, que tem entre seus objetivos proporcionar cidadania e senso crítico a todos os indivíduos, lidam com a diversidade de representações sociais que as ocupam, a partir da ótica da construção da consciência histórica? Como pode ser percebida a construção do conhecimento histórico a partir do encontro ou do confronto dessas expressões?

Após um período de ambientação, na escola e nas salas de aula, utilizando-se dos recursos de inspiração etnográfica, os licenciandos-bolsistas passaram a elaborar e a aplicar atividades didáticas, sob a supervisão da professora na escola. A linguagem cinematográfica foi escolhida para o trabalho com a temática do Império Romano, no primeiro ano do ensino médio. Mesmo com as dificuldades que os docentes enfrentam de acesso a equipamentos nas escolas públicas de São Paulo, o cinema tem sido, ao longo do tempo, um dos principais tipos de fonte histórica trabalhados nas aulas de História da escola básica brasileira. Katia Maria Abud, uma década atrás, já mencionava aspectos que conferiam veracidade a essa asserção:

Alguns fatores podem ser apontados como responsáveis por essa preferência: a enorme atração que a produção fílmica ainda exerce, a disseminação e a acessibilidade das fitas de vídeo, tanto em locadoras como nas videotecas de instituições educativas e nas próprias escolas. Por outro lado, a utilização de filmes tem sido facilitada pelas políticas públicas que têm como proposta a educação à distância (ABUD, 2003, p. 183).

O desenvolvimento exponencial das tecnologias audiovisuais no século XXI, bem como a maior acessibilidade da população brasileira aos suportes deste tipo de linguagem, promoveu ainda maior necessidade de os professores aprenderem a trabalhar o cinema enquanto produto cultural historicamente concebido. No caso da turma do primeiro ano do ensino médio da escola participante do projeto, foram utilizados os filmes Ben Hur (EUA, 1959) e Gladiador (EUA, 2000). O trabalho desenvolveu-se a partir da construção de um roteiro que priorizou a decupagem técnica e a concepção de História presente nos filmes com o intuito de possibilitar aos estudantes meios para sua interpretação. Nessa perspectiva, os filmes foram utilizados não como simples ilustração de um conteúdo histórico estudado (no caso, o Império Romano), mas como fontes históricas produzidas ao longo da história do cinema, as quais trazem a representação de um passado distante (no caso, a Antiguidade Clássica). Qual a relação entre a representação de passado contida nos documentos audiovisuais e seu contexto histórico de concepção? Tal relação propõe perspectivas de orientação para o tempo presente e para o futuro? Essas e outras questões possibilitaram o aprofundamento do trabalho dessa linguagem, enquanto documento investigado, para a construção do conhecimento histórico em sala de aula. 
Barca e Pereira (2013, p. 1224) discorrem a respeito da importância de relacionar a produção cinematográfica à vida dos estudantes com a finalidade de promover um processo paulatino de utilização da ciência histórica como meio de análise desse tipo de fonte:

A escola deve procurar promover a alfabetização das crianças e jovens nas linguagens cinematográficas, combatendo atitudes passivas em relação a este instrumento de poder. [...] Neste caso, o cinema desenvolve um importante papel de motivação e aprendizagem de conteúdos científicos e de aproximação das realidades sociais às escolares [...] (BARCA; PEREIRA, 2013, p. 1224).

Ora, a seleção dos filmes possibilitou ao bolsista-licenciando e à professora da turma o trabalho com diferentes representações do Império Romano. Explorar tais representações acerca do cotidiano romano da Antiguidade, por meio de obras fílmicas distantes quatro décadas entre si, permitiu aos estudantes a imersão analítica na diversidade representacional presente não somente nas questões de autoria e produção desse tipo de documento, como também nas características técnicas relacionadas ao momento de concepção dessas produções. Dessa forma, os estudantes puderam trabalhar aspectos da historicidade fundamentais para a compreensão dos interesses de orientação temporal subsumidos a cada produção cinematográfica. Compreender que cada documento trata da representação do passado a partir de necessidades de orientação de sua época de concepção; que tal representação depende de aspectos da produção, das técnicas pelas quais o filme é concebido; que relações de poder, ideologias, mentalidades, dentre outros interesses de apresentação de ideias ao público consumidor são inerentes à carga representacional da produção, é condição sine qua non para a qualificação da utilização desse tipo de linguagem, enquanto documento histórico, em sala de aula. Assim, conforme afirma Abud (2003, p. 188):

As imagens merecem estar em sala de aula porque sua leitura nunca é passiva. Elas provocam uma atividade psíquica intensa feita de seleções, de relações entre elementos da mesma obra, mas também com outras imagens e com representações criadas e expressas por formas de linguagem. A imagem fílmica situa-se em relação à outra, ausente, que se relaciona com a realidade que se supõe representada.

A turma de segundo ano do ensino médio, por sua vez, trabalhou a linguagem musical, mais precisamente o gênero rap, relacionando-o à temática da escravidão na guerra civil norte-americana.

Surgido nos bolsões de pobreza, situados na periferia de grandes cidades estadunidenses entre as décadas de 1970 e 1980 , o movimento rap $^{3}$ se fortaleceu devido ao declínio de investimentos sociais por parte de grupos politicamente conservadores que governaram os EUA, os quais optaram por uma política de transferência 
de renda dos pobres para os ricos (KELLNER, 2001, p. 230). Tal situação favoreceu a ampliação da desigualdade social, a queda do nível de emprego e de qualidade de vida dos menos favorecidos e, consequentemente, o aumento da violência. Isso proporcionou nos guetos urbanos, habitados em sua maioria por negros, o desenvolvimento de movimentos culturais denunciadores desse estado de coisas e, consequentemente, a construção de elementos identificadores dessas comunidades:

[...] há um forte componente de identificação grupal no rap, onde é possível encontrar a própria identidade dentro de comunidades mais amplas. Embora [...] a adoção de metáforas referentes à formação de gangues possam respaldar a existência de gangues de rua, também incentiva formas mais benignas de comunidade que servem de contrapartida positiva ao individualismo narcisista, endêmico na sociedade contemporânea (KELLNER, 2001, p. 239-240).

Diferentemente da cultura jovem dos anos 1960/1970 que utilizava um discurso revolucionário de ruptura estrutural política, econômica e cultural em relação à lógica de vida promovida pelos Estados-nações modernos, os jovens ligados a movimentos como o rap, na contemporaneidade, deparam-se com um mundo no qual os principais atores já não são esses estados eleitos democraticamente, mas grandes corporações financeiras não eleitas, não comprometidas com o espaço territorial que habitam, e interessadas somente em fortalecer um capitalismo globalizado que favoreça a multiplicação de seus lucros. Esse estado de coisas provocou ampla reestruturação econômica, o acirramento das desigualdades sociais e a ampliação da violência, alavancada pelo decréscimo em progressão geométrica dos empregos. Nesse contexto, os movimentos de cultura jovem como o rap usam novas estratégias para contestar a sociedade na qual estão inseridos: "A cultura jovem atual procede de uma premissa diferente. Ao invés de permanecer fora da sociedade, ela tenta trabalhar através dela, explorando e exacerbando suas contradições em criar imprevisíveis possibilidades para o futuro" (SPOSITO, 2000, p. 83).

Como voz da periferia, o movimento rap aglutina os jovens, expressando em suas letras a denúncia e o protesto contra o racismo, a discriminação, a desigualdade social e a violência policial. Tais temas compuseram a discussão dos estudantes do segundo ano do ensino médio a partir da audição de algumas músicas do grupo paulista Racionais $M C$ 's, acompanhadas da leitura de suas respectivas letras. O objetivo foi desencadear a discussão dos estudantes acerca dos problemas de seu próprio cotidiano, suas dúvidas, lamentos e situações de exclusão às quais são submetidos. Dotar de historicidade tais músicas, discutir as necessidades de orientação temporal dos próprios autores, seus objetivos, suas propostas político-sociais, a crítica estrutural a um sistema que exclui grande parte de pessoas, relegando-as às parcas condições de cidadania, compreendendo-as como desprovidas da capaci- 
dade de consumo e, portanto, passíveis do esquecimento por parte do Estado e do mercado, tornam-se premissas para que o presente possa ser relacionado com o passado, seja qual for o contexto e o conteúdo histórico estudado. Após esse processo de discussão e de compreensão, por parte dos estudantes, dos próprios problemas de exclusão vivenciados, cotidianamente, a partir da interpretação de canções datadas e localizadas historicamente, pôde-se promover a relação com o conteúdo histórico e as respectivas representações de exclusão do contexto da guerra civil norte-americana do século XIX.

Percebe-se que nas duas frentes os estudantes trabalharam com as questões da historicidade do documento, ou seja, com a influência que a autoria, o local de origem, o contexto histórico, etc., têm na construção de um produto cultural que dialoga com as questões de sua época. Dessa forma, ao mesmo tempo em que o estudante aprendia a temática da escravidão nos EUA do século XIX, era convidado a refletir acerca das semelhanças e diferenças com o ocorrido no Brasil colonial e imperial, bem como relacionava tais contextos às questões da consciência negra, e exclusão socioeconômica e étnico-racial na contemporaneidade. De outro lado, as influências da cultura romana da Antiguidade na contemporaneidade ocidental, tal como a política do pão e circo, ou mesmo aspectos da religiosidade, por exemplo, foram trabalhadas na análise dos filmes.

Outro aspecto a ser mencionado do projeto relaciona-se à aproximação dos estudantes da escola básica. O projeto com cinema na sala de aula permitiu aos alunos o conhecimento a respeito do conceito e de como pode ser criado um cineclube no espaço escolar, pois esses tiveram contato com um dos cineclubes da FCL-Unesp/Assis, por meio de uma visita ao campus, organizada pelo bolsista-licenciando, contando com o auxílio da professora participante, da coordenação pedagógica e da direção da escola. A atividade possibilitou maior aproximação dos estudantes dessa escola básica da Unesp, rompendo, de certa forma, o muro da desinformação e da exclusão, pois parte considerável dos estudantes de escolas públicas da cidade sequer entende que a Unesp é uma universidade pública e que está ao seu alcance. Tal ação, por si só, apresenta-se como extensionista.

Dessa forma, com uma metodologia que agrega recursos da etnografia à teoria das representações sociais, os bolsistas-licenciandos e a professora participante apropriaram-se de um repertório adequado para a análise da construção do conhecimento histórico por parte dos estudantes do ensino médio, a partir do percurso didático que desenvolveram. Em um segundo momento do trabalho, um pequeno questionário que investigava características socioeconômicas e culturais foi elaborado e aplicado às turmas escolhidas com o fim de construir um perfil discente facilitador do estudo das representações sociais originadas do grupo. A recolha de dados, somada ao acompa- 
nhamento de aulas, por parte dos bolsistas, possibilitou (re)conhecer a sala de aula em sua dinâmica, fator que facilitou o processo de interpretação das representações (re)construídas a partir do encontro/confronto com o ensino da História.

É nesse sentido que se insere a teoria da consciência histórica, a qual possibilitará, no terceiro momento do projeto, o desenvolvimento de pesquisas que promovam a verificação da influência (ou não) do processo de trabalho com diferentes linguagens, enquanto fontes históricas, na qualificação da construção do conhecimento histórico dos estudantes.

Para o historiador e filósofo da História, Jörn Rüsen, consciência histórica é a "[...] suma das operações mentais com as quais os homens interpretam sua experiência da evolução temporal de seu mundo e de si mesmos de forma tal que possam orientar, intencionalmente, sua vida prática no tempo" (RÜSEN, 2001, p. 57).

As operações mentais utilizadas para a elaboração da consciência histórica dependem de um processo de desenvolvimento da capacidade de pensar historicamente e, por conseguinte, adquirir conhecimento histórico. No entender de Rüsen, o pensamento histórico é desenvolvido a partir da necessidade de resolução de problemas de orientação no presente. Tal desenvolvimento requer um processo construído cognitivamente por meio de etapas que formam uma matriz disciplinar que se caracteriza por apresentar a História como uma disciplina especializada científica composta por um sistema de princípios que mostram as especificidades do pensamento histórico. ${ }^{4}$ Acredita-se que a ciência da História pode influenciar os seres humanos a orientarem-se praticamente no tempo, ou seja, historicamente. ${ }^{5}$ Nesse sentido, ocorre uma relação dialética (e dialógica) entre a História pesquisada e elaborada nos meios acadêmicos e a necessidade do ser humano em utilizar a História em seu cotidiano.

[...] a teoria da História abrange, com esses interesses, os pressupostos da vida cotidiana e os fundamentos da ciência da história justamente no ponto em que o pensamento histórico é fundamental para os homens se haverem com suas próprias vidas, na medida em que a compreensão do presente e a projeção do futuro somente seriam possíveis com a recuperação do passado (RÜSEN, 2001, p. 30).

A consciência histórica pode ser entendida como fenômeno que emerge do encontro do pensamento histórico científico com o pensamento histórico geral. Como tal, pode ser averiguada sua presença nos indivíduos, por meio da análise do cotidiano de suas vidas, com o objetivo de apreender as operações mentais que os fazem pensar historicamente. Essas operações somente tornam-se evidentes quando consegue-se apurar seu grau de importância na práxis de vida, o sentido de sua ocorrência e os resultados dela gerados.

Como fenômeno da vida, ou seja, uma forma de consciência humana que está diretamente ligada à vida prática, a consciência histórica está fundamentada na neces- 
sidade que os seres humanos têm de construir interpretações diante de suas próprias mudanças e de seu mundo, com o intuito de exercer o domínio dessas transformações por meio de suas ações, as quais contemplam as principais funções da consciência histórica: orientação prática e construção de identidade. Dessa forma, a consciência histórica transcende "[...] a distinção entre teoria e práxis, entre conhecimento histórico no âmbito da ciência da história e aplicação desse conhecimento fora da ciência, e busca conexão íntima entre o pensamento e a vida, na qual (suas) operações são reconhecidas como produtos da vida prática concreta" (RÜSEN, 2001, p. 55).

Finalmente, os bolsistas elaboraram e aplicaram um instrumento cognitivo que possibilitou a geração de narrativas dos discentes acerca do que estudaram com a finalidade de gerar representações sociais a serem analisadas. Os dados possibilitaram a criação de projetos de pesquisa de iniciação científica aos licenciandos-bolsistas que estão em processo de escrita e de submissão a agências de fomento.

$\mathrm{O}$ resultado dessas pesquisas, fundamentadas em todo processo de trabalho desenvolvido, certamente auxiliará os professores e a professora da escola em futuras ações metodológicas realizadas junto a seus alunos, pois, além de contribuir na elaboração do material didático produzido nesse contexto, auxilia na interpretação do perfil socioeconômico, cultural e cognitivo do grupo de estudantes. Além disso, a análise das representações construídas no espaço escolar, a partir do uso de filmes e músicas, à luz da teoria da consciência histórica tal como Rüsen propõe, possibilitará perceber aspectos da construção do conhecimento histórico por meio do cruzamento do saber historiográfico acadêmico com o saber escolar.

As ações derivadas da aplicação deste projeto demonstram que a didática da História contemporânea coloca em pauta a necessidade de formação de professores que se compreendam como pesquisadores constantes de seu espaço de trabalho, pois para essa não há dissociação entre pesquisa e docência. Aos futuros e atuais professores de História, portanto, se reserva o desafio de desenvolvimento de atividades que permitam aos estudantes a aprendizagem da História por meio da análise da diversidade de fontes (escritas, imagéticas, sonoras, audiovisuais, da cultura material, entre outras), pois é nessa ação didática, mediada pela racionalidade histórica, que reside a função de promover o embate com a produção cultural, historicamente concebida, a fim de criar possibilidades de reflexão a respeito da contemporaneidade.

Nessa perspectiva, a aprendizagem histórica ocorre por meio de um processo gerador de ações que combina a seleção de informações, o exercício hermenêutico e a criação de perspectivas de orientação temporal no cotidiano vivido. A aplicação do projeto visa não somente a elaboração de atividades, mas também a possibilidade de verificar em que medida tais ações didáticas proporcionam maior mobilização das operações do raciocínio histórico, por parte dos estudantes, de forma que 
as representações sociais derivadas desse processo possam ser objeto de reflexão constante dos docentes.

Dessa forma, o projeto vivencia a relação entre ensino, pesquisa e extensão, pois aproxima o conhecimento gerado na universidade dos saberes derivados da vivência na escola básica, constituindo, para estudantes, professores e futuros professores, um importante espaço de reflexão acerca da relevância do modo de pensar próprio da História que contemple o enfrentamento das questões cotidianas.

\section{The history classroom as a place of education, research and extension}

\section{Abstract}

The paper presents a work project developed by the Laboratory of Studies and Research in History Teaching of Unesp/campus Assis (LEPEDIH), which the classroom is understood as a place of construction of historical knowledge through experiences, between students, teachers and future teachers that add teaching, research and extension, in a way that occur the approach between university and public elementary schools in order that participants can relate the study of history with their own life.

Keywords: Historical consciousness. Social representations. Educational ethnography

Notas

1 O Núcleo de Ensino, por ser um projeto interior à Unesp obviamente é muito menos ambicioso e abrangente que o Pibid. Diferentemente do segundo, que se trata de uma política governamental (que tem se ampliado com vistas a se tornar uma política "de Estado") provedora de bolsas para licenciandos, professores das escolas de educação básica e docentes da universidade que atuam em subprojetos ou na administração geral institucional, o primeiro apenas provê bolsas para os licenciandos. Entretanto, tal programa tem se mostrado producente ao longo dos anos e atuado paralelamente ao Pibid na mesma Universidade, desde o edital de 2009 do projeto federal, o primeiro do qual a Unesp participou.

2 O espaço das experiências é definido por Koselleck (2006) como o montante de experiências individuais e coletivas, pessoais e alheias, passíveis de serem rememoradas, as quais são transmitidas de geração em geração por diferentes meios. Experiências que se acumulam em diversos tempos e espaços e têm como fim nutrir as expectativas dos sujeitos históricos de acordo com as demandas de orientação no tempo.

3 KELLNER, D. A cultura da mídia - estudos culturais: identidade e política entre o moderno e o pós-moderno. Bauru: EDUSC, 2001, p. 230. O autor conceitua o rap como "uma forma de falar ou fazer música em que o R significa rima e ritmo, e o P, poesia - e em alguns casos política." Trata-se de uma categoria da cultura Hip Hop. Além do rap, o Hip Hop engloba a dança, a grafitagem, estilos de roupa, modos de falar e outras expressões culturais.

4 Rüsen utiliza essa ideia criada por Thomas Kuhn (KUHN, T. A estrutura das revoluções científicas. São Paulo: Perspectiva, 1975).

5 A ciência da História para Rüsen (Geschichtswissenschaft em alemão) tem o sentido da História como produto da operação científica da História na academia. Já o termo alemão Geschichte, foi utilizado para a História no sentido de processo temporal do agir racional dos seres humanos - conforme nota do tradutor do texto (RÜSEN, 2001, p. 11). 


\section{Referências}

ABUD, Katia Maria. A construção de uma didática da História: algumas ideias sobre a utilização de filmes no ensino. In: História, São Paulo, n. 22, n. 1, 2003.

BARCA, Isabel; PEREIRA, Pedro. O cinema na aula de História: uma exploração com alunos do $8^{\circ}$ ano. In: PRATS, Joaquín; BARCA, Isabel; FACAL, Ramón (Orgs.) Anais do V Simpósio Internacional de Didáctica de las Ciencias Sociales en el ámbito Iberoamericano e Congresso Internacional das XIII Jornadas de Educação Histórica, Barcelona/Braga, CIED (Centro de Investigação em Educação) da Universidade do Minho, 2013. p. 1222-1232.

BRAUDEL, Fernand. História e ciências sociais. A longa duração. In. Escritos sobre a História. São Paulo: Ed. Perspectiva, 1992. p. 41-78.

BUENO, Belmira Oliveira. Entre a Antropologia e a História: uma perspectiva para a etnografia educacional. In: Perspectiva, Florianópolis, v. 25, n. 2, p. 471-501, jul./dez. 2007.

CHARTIER, Roger. A história cultural: entre práticas e representações. Lisboa: Difel, 1990.

ELIAS, N.; SCOTSON, J. L. Os estabelecidos e os outsiders: sociologia das relações de poder a partir de uma pequena comunidade. Rio de Janeiro: Jorge Zahar Ed., 2001.

EZPELETA, Juzta; ROCKWELL, Elsie. Pesquisa participante. São Paulo: Cortez Editores/Autores Associados, 1986.

GEERTZ, Clifford. A interpretação das culturas. Rio de Janeiro: LTC, 2012.

JODELET, Denise. As representações sociais. Rio de Janeiro: EdUERJ, 2001.

KELLNER, Douglas. A cultura da mídia - estudos culturais: identidade e política entre o moderno e o pós-moderno. Bauru: EDUSC, 2001.

KOSELLECK, Reinhart. Futuro Passado: contribuição à semântica dos tempos históricos. Rio de Janeiro: Contraponto \& Ed. PUC-Rio, 2006.

MOSCOVICI, Serge. La psychanalyse, son image et son public. Paris: Presses Universitaires de France, 1976.

. Representações sociais: investigações em psicologia social. 3.ed. Petrópolis: Vozes, 2003.

PESAVENTO, Sandra Jatahy. Em busca de uma outra história: imaginando o imaginário. Revista Brasileira de História, São Paulo, v. 15, n. 29, p. 9-27, 1995.

ROCKWELL, Elsie. La relevancia da etnografía para la transformación de la escuela. In: $M e$ morias del tercer Seminario Nacional de Investigación en Educación. Bogotá - Colombia: ICPES/ Centro de Investigación de la Universidad Pedagógica, 1986. p. 15-20.

RÜSEN, Jörn. Razão histórica - teoria da história I: fundamentos da ciência histórica. Trad. Estevão de Rezende Martins. Brasília: Ed. Universidade de Brasília, 2001.

SPOSITO, Marília Pontes. Algumas hipóteses sobre as relações entre movimentos sociais, juventude e educação. Revista Brasileira de Educação, São Paulo, n. 13, p. 73-94, jan./abr. 2000. 